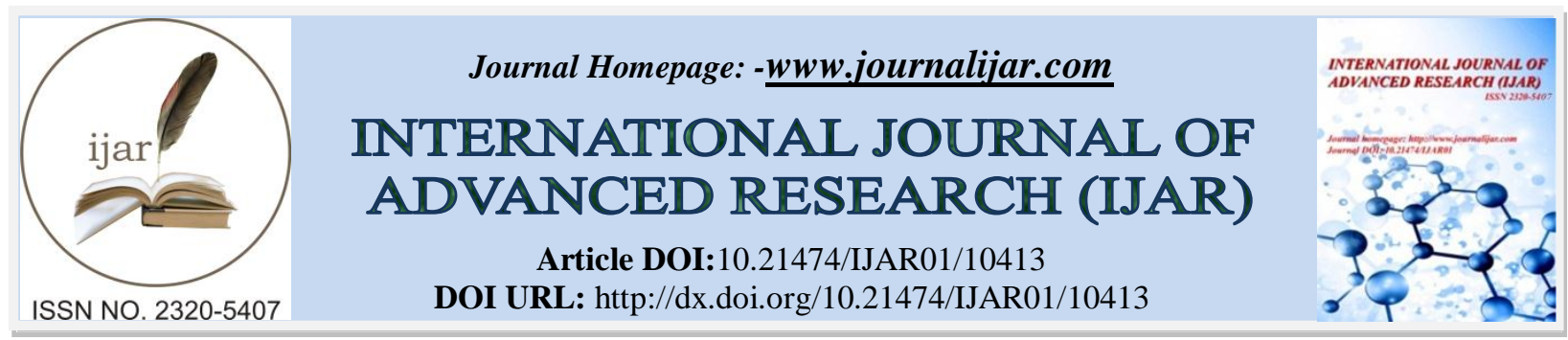

RESEARCH ARTICLE

\title{
IS ENBLOC LIGATION OF RENAL PEDICLE SAFE DURING LAPAROSCOPIC NEPHRECTOMY?
}

\author{
Neel Patel
}

\section{Manuscript Info}

Abstract

Manuscript History

Received: 30 November 2019

Final Accepted: 31 December 2019

Published: January 2020

Copy Right, IJAR, 2020,. All rights reserved.

\section{Introduction:-}

Laparoscopic approach for nephrectomy is widely performed now days. Both open and laparoscopic approach involves mobilization, individual ligation and division of renal artery and vein as standard of care. ${ }^{1}$ Enbloc ligation of renal vessel has been associated with rare complication of post nephrectomy AV fistula. Other causes of Post nephrectomy AVF are inflammation, infection, inadequate ligation and transfixation sutures. ${ }^{2}$ Earlier braided silk was used for enbloc ligation which resulted in bacterial accumulation in interstices of suture which caused tissue reactivity and infection.

Lacombe $^{3}$ that noted a high rate of en bloc ligation among the 62 cases of postnephrectomy AVF reported to date. Only in 14 of 62 cases details of ligation were available. Out of 14 cases 12 had en bloc ligation of renal pedicle and 2 had individual ligation. In 3 cases transfixing sutures were used. Majority of these nephrectomies were performed for infectious etiology which allowed surface accumulation of bacteria and capillary penetration of bacteria into interstices of the suture and favored infection. Resultant microabscess then eroded into adjacent vessel and caused fistula formation.

Now a days titanium endovascular staplers are being used for en bloc ligation of renal hilum, which has demonstrated excellent biocompatibility by causing minimal inflammatory reaction. ${ }^{4}$ Recently Rapp et al. ${ }^{5}$ reported their experience of 26 cases of difficult nephrectomies secondary to difficult hilar dissection and/or bleeding. No patient had any complication during follow up evaluation.

Materials and Methods:

We retrospectively evaluated our experience with en bloc ligation of the renal hilum during laparoscopic nephrectomy and compared the outcomes with those who underwent separate ligation of hilar vessels.

We included cases of laparoscopic nephrectomy as well as nephroureterectomy for non inflammatory conditions for which 1 year follow up data was available. We used the Endopath Linear Cutter (Ethicon, Cincinnati,

Ohio) with 45-mm vascular loads for all cases.

A total of 80 patients ( 80 renal units) were available for analysis. We decided intraoperatively to ligate vessels enbloc or separately.

We reviewed medical records to determine the method of hilar control, intra operative blood loss, histopathology results and complications during follow up. We recorded patients' blood pressure and heart rate during follow up. 
Patients were assessed for complications of AVF, which includes tachycardia, diastolic hypertension, abdominal bruit, congestive cardiac failure, and other cardiovascular complications.

We divided patients into two groups. Group A where en bloc ligation of renal vessel was done and group B where individual ligation of renal vessel was done.

\begin{tabular}{|l|l|l|l|}
\hline Characteristic & Group A & Group B & P value \\
\hline Patients (n) & 44 & 36 & - \\
\hline Age & 55.4 & 55.2 & 0.47 \\
\hline Right sided mass & 20 & 16 & - \\
\hline Left sided mass & 24 & 20 & - \\
\hline Mean tumor Size & 4.69 & 4.72 & 0.44 \\
\hline Pathologic type (n) & & & \\
\hline Non functional & 6 & 4 & - \\
\hline RCC & 36 & 30 & - \\
\hline AML & 1 & 1 & - \\
\hline Oncocytoma & 1 & 1 & - \\
\hline
\end{tabular}

Table 1:- Patient characteristics.

\begin{tabular}{|l|l|l|l|}
\hline Characteristic & Group A & Group B & P Value \\
\hline Estimated blood loss (ml) & $182 \mathrm{ml}$ & $253 \mathrm{ml}$ & 0.0001 \\
\hline Mean diastolic BP & $76 \mathrm{mmhg}$ & $76 \mathrm{mmhg}$ & 0.26 \\
\hline Mean heart rate (bpm) & 76 & 77 & 0.21 \\
\hline Post operative bleeding & None & None & - \\
\hline Abdominal bruits & None & None & - \\
\hline Mean tumor size & $4.1 \mathrm{~cm}$ & $3.9 \mathrm{~cm}$ & 0.391 \\
\hline Conversion to open surgery $(\%)$ & $4.5 \%$ & $5.5 \%$ & 0.75 \\
\hline
\end{tabular}

Table 2:- Outcome of Surgery.

\section{Results:-}

In Table 1 we have listed the patient characteristics of our case series. No significant differences were observed with regard to parameters such as age, tumor size, or nephrectomy side. In Table 2 we have listed the operative and postoperative characteristics of patients undergoing en bloc or individual hilar vessels ligation.

Mean Estimated blood loss was lower in enbloc group (182 ml) versus individual group (253 ml) but this did not reach the statistical significance. No differences were observed with regard to diastolic blood pressure $(76 \mathrm{~mm} \mathrm{Hg}$ versus $76 \mathrm{~mm} \mathrm{Hg}$ ) or heart rate $(76 \mathrm{bpm}$ versus $77 \mathrm{bpm}$ ) between the en bloc and separate groups, and no patient in either group exhibited clinical signs or symptoms of AVF, such as an abdominal bruit. Conversion to open surgeries was similar in both groups. (p value 0.75 )

\section{Discussion:-}

AVF is a rare complication after nephrectomy, and approximately 60 cases reported in published studies since 1934. ${ }^{3}$ En bloc ligation as the etiology of AVF formation has stemmed from retrospective analysis of these cases. Several other factors apart from mode of ligation contribute to formation of AVF such as infections, trauma and inflammatory conditions. In the retrospective review by Lacombe, ${ }^{3}$ the mode of ligation was only known in 14 of 62 cases. Also, technical difficulties prevented adequate operative hemostasis in 3 cases, resulting in temporary packing of the surgical bed. ${ }^{3}$

Other mechanisms of AVF formation in addition to infection or inflammation have been proposed like application of transfixation sutures to the ligature, which may inadvertently create a connection between artery and vein. Fistulas can form in cases where wound was packed or clamps were left in place after wound closure because of uncontrolled bleeding; this could indicate inadequate ligation of the vessels. ${ }^{6,7}$ Even separately ligated renal vessels may retract within their sheath after transection and become adherent in cases of inflammation that can predispose the vessels to AVF formation. 
Another theory postulates the formation of pseudoaneurysm at the stump of renal artery after ligation and transection, which may then erode into the adjacent vein, irrespective of the method of the artery ligation. ${ }^{8}$

Similarly, in congenital or idiopathic renal artery aneurysms ( $0.1 \%$ prevalence, mean age 51 years, range 13 to 78 ), the renal artery aneurysms have been shown to erode into the adjacent renal vein creating an AVF. ${ }^{8,9}$

In our series of 80 laparoscopic nephrectomy cases, we found no increased operative risk, postoperative sequelae, or complications at a follow-up of approximately 2 years in the 44 cases of en bloc ligation of the renal hilum. Rapp et al. ${ }^{10}$ reported 26 cases of en bloc ligation without complications.

Less hilar dissection in en bloc ligation cases result in less blood loss, shorter surgery duration and lower risk of conversion to open procedure. It is in accordance in our case series where EBL and conversion to open surgery rate is lower in en bloc ligation group. This is especially useful in large renal mass group where hilar dissection may be difficult and might result in more blood loss. Also, by avoiding dissection in perinephric fat between artery and vein more adventitial tissue is left on the vessels. Thus limiting distensibility of vessels thereby decreasing intravascular tension and propensity for formation of pseudoanuerysm and AVF.

Enbloc ligation is a common practice for patients undergoing laparoscopic splenectomy excluding cases of splenomegaly. Several centers have reported on the efficacy of this method, with associated reduced blood loss, shorter procedure times, and no incidence of splenic AVF. ${ }^{11-13}$ In addition, in gynecologic surgery, both the cardinal ligaments (composed of a network of multiple tortuous arteries and veins) and the uterine artery and vein are routinely ligated and transected en bloc during hysterectomy. Although fistulas between the uterine vessels have been reported after hysterectomy, this does not appear to be increased with en bloc ligation. ${ }^{14,15}$

\section{Conclusion:-}

Post nephrectomy AVF is a rare complication and is usually associated with infectious or inflammatory pathology. No evidence has been shown of AVF development after human nephrectomy using en bloc ligation of renal hilum using titanium clips. En bloc ligation allows for more secure, ready, and expeditious control of the hilum and may avoid unnecessary hilar dissection and result in less blood loss and lower risk of conversion to open surgery especially in large complex cases.

\section{Reference:-}

1. Saranchuk JW, and Savage SJ: Laparoscopic radical nephrectomy: current status. BJU Int 95(suppl 2): 21-26, 2005.

2. Goldstein AG, Delaurentis DA, and Schwartz AJ: Post-nephrectomy arteriovenous fistula. J Urol 98: 44-47, 1967.

3. Lacombe M: Renal arteriovenous fistula following nephrectomy. Urology 25: 13-16, 1985

4. Scheidbach H, Tannapfel A, Schmidt U, et al: Influence of titanium coating on the biocompatibility of a heavyweight polypropylene mesh: an animal experimental model. Eur Surg Res 36: 313-317, 2004.

5. Rapp DE, Orvieto MA, Gerber GS, et al: En bloc stapling of renal hilum during laparoscopic nephrectomy and nephroureterectomy. Urology 64: 655-659, 2004.

6. Herman SD, Radecki PD, Friedman AC, et al: Postnephrectomy pseudoaneurysm with arteriovenous fistula. Urol Radiol 9: 225-227, 1988.

7. Vick B, Nelson D, and Cordell R: Postnephrectomy arteriovenous fistula. Am J Surg 111: 262-264, 1966.

8. Sheiner NM, Palayew M, Marinho M, et al: Postnephrectomy

9. arteriovenous fistula: report of a case and review of the literature. J Cardiovasc Surg (Torino) 8: 534-535.

10. Henke PK, Cardneau JD, Welling TH III, et al: Renal artery

11. aneurysms: a 35-year clinical experience with 252 aneurysms in 168 patients. Ann Surg 234: 454-462, 2001.

12. Rapp DE, Orvieto MA, Gerber GS, et al: En bloc stapling of renal hilum during laparoscopic nephrectomy and nephroureterectomy. Urology 64: 655-659, 2004.

13. Park AE, Birgisson G, Mastrangelo MJ, et al: Laparoscopic splenectomy: outcomes and lessons learned from over 200 cases. Surgery 128: 660-667, 2000.

14. Brothers TE, Stanley JC, and Zelenock GB: Splenic arteriovenous fistula. Int Surg 80: 189-194, 1995.

15. Szold A, Sagi B, Merhav H, et al: Optimizing laparoscopic splenectomy: technical details and experience in 59 patients. Surg Endosc 12: 1078-1081, 1998.

16. Gershenson DM (Ed): Operative Gynecology, 2nd ed. Philadelphia, WB Saunders, 2001. 